\title{
Article \\ Study on Stress Field Distribution during the Construction of a Group of Tunnels Using the Pile-Beam-Arch Method
}

\author{
Bo Huang ${ }^{1, *(\mathbb{D})}$, Yihan Du ${ }^{1, *}$, Yu Zeng ${ }^{2}$, Bing Cao ${ }^{1}$, Yu Zou $^{2}$ and Qian Yu ${ }^{1}$ \\ 1 School of Architecture and Civil Engineering, Anhui Polytechnic University, Wuhu 241000, China; \\ caobing.0427@163.com (B.C.); y13215527219@163.com (Q.Y.) \\ 2 School of Mechanics and Civil Engineering, China University of Mining and Technology, \\ Beijing 100083, China; zenyu0808@163.com (Y.Z.); glimmer1007@163.com (Y.Z.) \\ * Correspondence: huangbo@ahpu.edu.cn (B.H.); duyihan00@163.com (Y.D.)
}

Citation: Huang, B.; Du, Y.; Zeng, Y.; Cao, B.; Zou, Y.; Yu, Q. Study on Stress Field Distribution during the Construction of a Group of Tunnels Using the Pile-Beam-Arch Method. Buildings 2022, 12, 300. https:/ / doi.org/10.3390/buildings12030300

Academic Editors: Shuli Fan and Qiang Xu

Received: 25 January 2022

Accepted: 2 March 2022

Published: 4 March 2022

Publisher's Note: MDPI stays neutral with regard to jurisdictional claims in published maps and institutional affiliations.

Copyright: (C) 2022 by the authors. Licensee MDPI, Basel, Switzerland. This article is an open access article distributed under the terms and conditions of the Creative Commons Attribution (CC BY) license (https:// creativecommons.org/licenses/by/ $4.0 /)$.

\begin{abstract}
To study stress field distributions during the construction of a group of tunnels using the pile-beam-arch method, the excavation for an underground station of Beijing subway line 7 was taken as an engineering problem, and a numerical structural model of a tunnel group was built with the aid of software. In this model, four stress-monitoring planes were set up to extract the data obtained from monitoring stress. The construction of the pilot tunnels was simulated according to six established construction schemes, and images were generated for the stress field distribution on each monitoring plane using different schemes. Finally, a verification of physical model tests was carried out. The results show that the effect of excavation on vertical stress in pilot tunnels has a range that is essentially equal to twice the width of the station. After the excavation of pilot tunnels, peaks appeared both at the tops of the pilot tunnels and between the bottoms of the tunnels; moreover, valleys appeared both at the bottoms of the pilot tunnels and between the tops of the tunnels. Pilot tunnels located at the top of the group were less affected during excavation than the tunnels located at the bottom of the group both in stress concentration factor and in the point of extreme stress. Finally, the model verified the numerical simulation results of the stress variation law.
\end{abstract}

Keywords: pile-beam-arch method; pilot tunnel excavation; stress field; numerical simulation; model test

\section{Introduction}

Due to the large size of subway stations and the small thickness of the overlying soil, excavation of a new subway station causes significant ground settlement. To reduce the amount of ground movement caused by tunnel construction in urban areas, scholars have developed a series of new construction methods over the years, with underground construction technology developing rapidly [1-5]. The pile-beam-arch method, a common method applied during subway station construction, overcomes the disadvantages of hydrogeological conditions, the shallowness of stations in relation to the ground above, and aboveground traffic during the construction of a station.

The pile-beam-arch method is a combination of the traditional construction method of the ground frame structure and the undermining method. During underground excavation, the side piles, middle pillars, bottom beams, top beams, and vaults of the station are constructed in advance to provide support during the formation of the piles, beams, vaults, and arch (PBA) of the frame of the final system and to bear external load during the construction process. Then, under the protection of these vaults and side piles, the soil is excavated layer by layer to construct the internal structure and finally to form the permanent bearing system composed of outer side piles, the primary support vault, and the secondary lining of an inner layer [6]. Compared with the conventional undermining method, when the PBA method is used to construct the station, the cross section of the station is almost rectangular, so the usable area of the cross section is large. At the same 
time, it has the advantages of safe construction, less temporary support, relatively low cost, and short construction timeline. Thus, the PBA method is an excavation method worth considering.

At present, the research directions for the PBA method are numerous. Among them are targeted research on the key nodes of the construction process, optimization of the construction sequence, and research on the law of ground settlement caused by station construction. When the PBA method is applied to excavation during subway construction, a small pilot tunnel can be excavated first, and then the soil can be excavated safely due to this initial support, which can reduce disturbance to the soil above as much as possible [7-10]. Relevant results have shown that the most important step during construction that causes settlement using the PBA method is the excavation of the pilot tunnels [11-14]. In the construction of multiple pilot tunnels, the choice of operation is the dominant factor affecting surface settlement. The construction principle "short footage and frequent support" is reliable [15]. In the construction process, the excavation sequence of small pilot tunnels must be reasonable, with pilot tunnels located at the top of the group being excavated first, which reduces settlement to the greatest extent and ensures safety during construction and in surrounding buildings [16]. Adopting the excavation sequences "up and then down" and "side and then center" can effectively reduce the group hole effect between pilot tunnels, effectively control surface deformation, and limit the range of the plastic zone [17]. Moreover, compared with the bottom-up method, the top-down method used for construction of the secondary lining significantly reduces the internal force exerted on supporting structures and the amount of surface settlement [18]. In the construction of double-layer tunnels and double-guide tunnels, different excavation sequences have little effect on the final surface settlement. Excavating the same side of a guide tunnel at first can reduce the distance from the point of inversion. The maximum settlement point is biased towards the beginning of the tunnel. Excavating tunnels located at the top of the group first can reduce the proportion of ground settlement caused by excavation of the lower tunnels [19]. The most reasonable excavation sequence is determined by comparing and studying the effect of different distances between the pilot tunnels and sequences of excavation on the surface settlement [20].

Based on the above analysis, current research on the PBA construction method mostly focuses on the settlement during pilot tunnel construction and rarely involves the study of soil stress during construction. However, the disturbance of surrounding soil during excavation of the pilot tunnel cannot be ignored. Excessive excavation disturbances cause stress failure, causing soil collapse and large amounts of ground settlement.

This paper takes Daguanying station on Beijing subway line 7 as an example problem and uses numerical simulations and modeling to study the stress field distribution of key soil layers from small pilot tunnels under different excavation schemes, comparing and analyzing the changes in stress for the soil during excavation. The objectives of this study are (1) to determine the similarities and differences of the effects of different excavation schemes on the stress field in the soil, (2) to determine the similarities and differences of the stress field changes in the soil layer at different locations, and (3) from the perspective of the stress field, to determine the scope of the effects of pilot tunnel excavation on the surrounding environment and buildings. This study has a certain guiding significance for determining the best excavation plan for pilot tunnels and for judging areas deemed dangerous for excavation.

\section{Case Study}

As a follow up to previous work [19], Daguanying station on Beijing subway line 7 has been taken as an engineering problem. The length of the station is $236 \mathrm{~m}$, the width is $22.9 \mathrm{~m}$, and the height is $15.15 \mathrm{~m}$. The thickness of the soil between the surface and the tunnel is approximately $9 \mathrm{~m}$. The station has a straight wall and an underground double-layer three-span structure. The main structure of the station was constructed using the pile-beam-arch method, and eight pilot tunnels were excavated during pilot heading 
construction. An example pilot tunnel constructed at the site is shown in Figure 1a. The structural section is shown in Figure 1b.

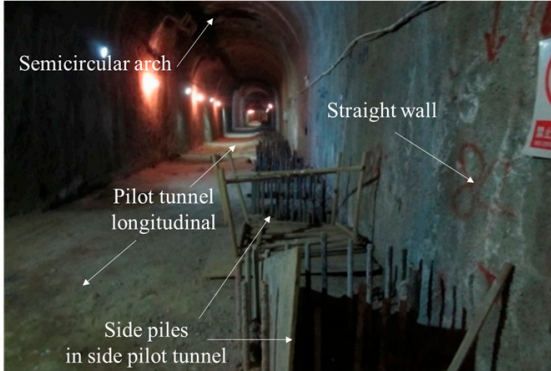

(a)

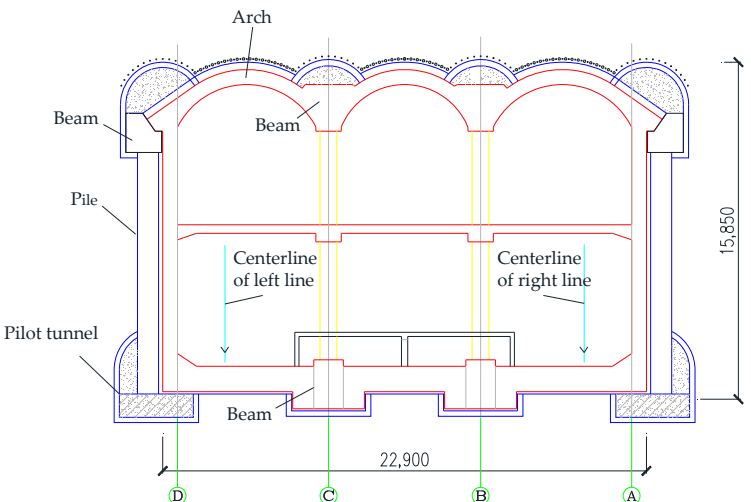

(b)

Figure 1. Daguanying station: (a) pilot tunnel at the construction site and (b) structural section (unit: $\mathrm{mm}$ ).

Four soil layers were within the range of this station: artificial soil was distributed from the ground $(0 \mathrm{~m})$ down to $9 \mathrm{~m}$; pebble bed 1 was distributed from $9 \mathrm{~m}$ down to $13 \mathrm{~m}$; pebble bed 2 was distributed from 13 to $23.6 \mathrm{~m}$; strongly weathered conglomerate and mudstone were distributed from 23.6 to $46.3 \mathrm{~m}$. The parameters of the soil mass and primary lining used in this study are shown in Table 1.

Table 1. Parameters of the soil mass and primary lining.

\begin{tabular}{|c|c|c|c|c|c|c|c|}
\hline Items & $\begin{array}{l}\text { Elastic } \\
\text { Modulus } \\
\text { E/MPa }\end{array}$ & $\begin{array}{l}\text { Poisson's } \\
\text { Ratio }\end{array}$ & $\begin{array}{l}\text { Cohesion } \\
\mathrm{c} / \mathrm{kPa}\end{array}$ & $\begin{array}{c}\text { Internal } \\
\text { Friction } \\
\left.\text { Angle/( }{ }^{\circ}\right)\end{array}$ & Density/(kg· $\left.\mathbf{m}^{-3}\right)$ & $\begin{array}{c}\text { Bulk } \\
\text { Modulus/MPa }\end{array}$ & $\begin{array}{c}\text { Shear } \\
\text { Modulus/MPa }\end{array}$ \\
\hline artificial soil & 23 & 0.3 & 10 & 18 & 1950 & 19.17 & 8.85 \\
\hline pebble bed 1 & 63 & 0.25 & 0.5 & 40 & 2070 & 42 & 25.2 \\
\hline $\begin{array}{c}\text { pebble bed } 2 \\
\text { strongly weathered }\end{array}$ & 75 & 0.23 & 0.8 & 32 & 2000 & 32.5 & 30.5 \\
\hline $\begin{array}{l}\text { conglomerate and } \\
\text { mudstone }\end{array}$ & 105 & 0.26 & 0 & 35 & 2150 & 72.9 & 41.7 \\
\hline grid steel frame & 25,000 & 0.3 & & & 2300 & & \\
\hline
\end{tabular}

\section{Model}

\subsection{Numerical Model}

The numerical model was built according to the engineering problem as shown in Figure 2a. The dimensions of the model are $136 \mathrm{~m}$ (transverse, $\mathrm{x}$-axis) $\times 20 \mathrm{~m}$ (longitudinal, $\mathrm{y}$-axis) $\times 46.3 \mathrm{~m}$ (vertical, z-axis). Every small pilot tunnel was numbered as shown in Figure $2 b$ for convenience. The relative positions of the pilot tunnels and soil layers are presented in Figure 3.

\subsection{Setting Monitoring Points}

To record the changes in stress in the soil, monitoring points need to be arranged in a numerical model. As shown in Figure 4, four monitoring planes (P1 to P4) were set up: P1 was located above the upper pilot tunnels $(\mathrm{z}=4.5 \mathrm{~m})$, P2 was located below the upper pilot tunnels $(z=0 \mathrm{~m})$, P3 was located above the lower pilot tunnels $(z=-8.3 \mathrm{~m})$, and P4 was located below the lower pilot tunnels $(\mathrm{z}=-12.8 \mathrm{~m})$. The monitoring points were arranged as a grid on each monitoring plane. In detail, the grid consisted of $1 \mathrm{~m}$ intervals for a total of $18 \mathrm{~m}$ on both sides of the station, which was taken as the centerline ( $\mathrm{y}=-18$ to $18 \mathrm{~m}$ ), and $2 \mathrm{~m}$ intervals for all other sides. 


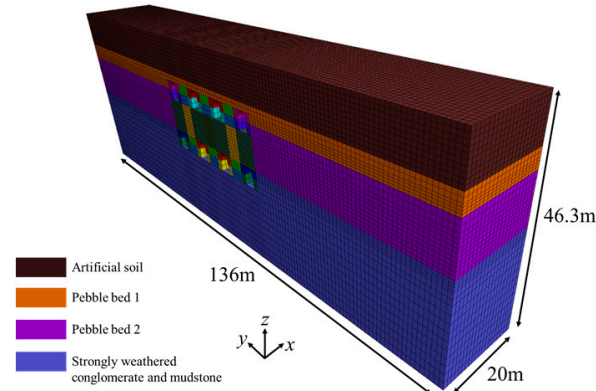

(a)

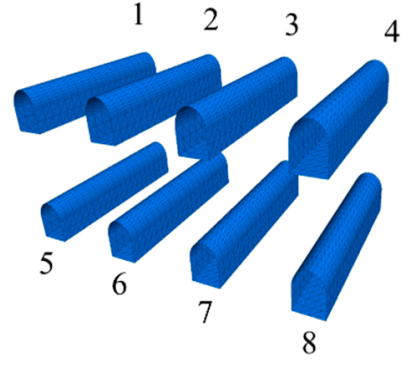

(b)

Figure 2. Numerical model: (a) model and (b) serial numbers of the pilot tunnels.

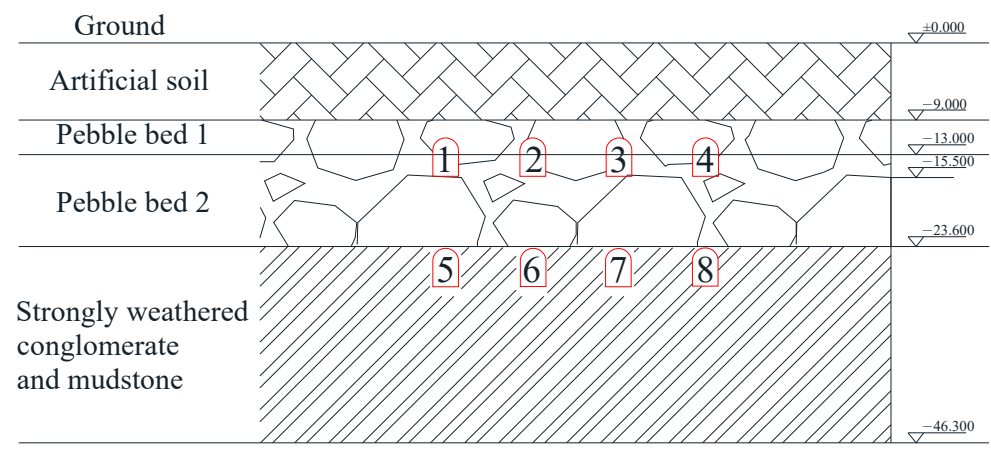

Figure 3. Positions of the tunnels relative to one another.

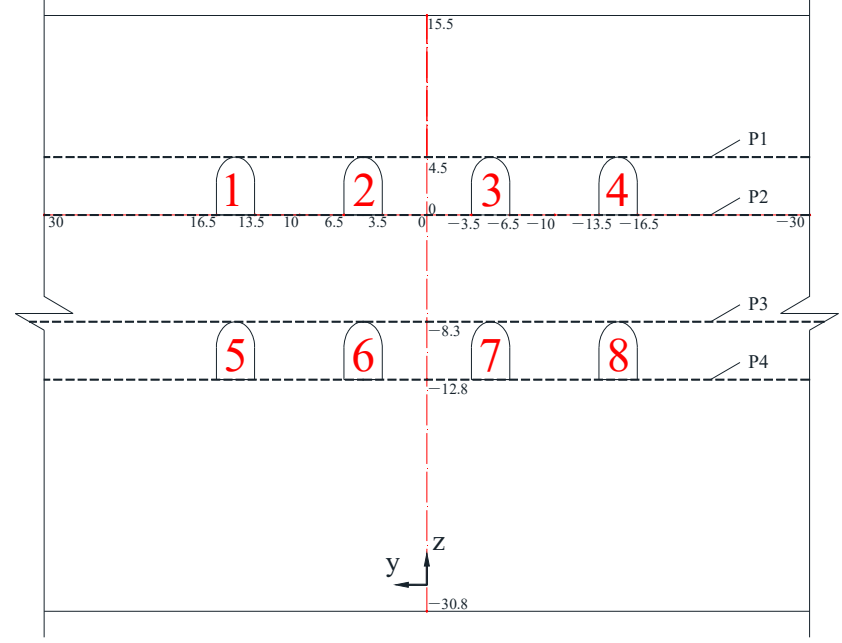

Figure 4. Monitoring planes.

\section{Influence of Excavation Sequences on Stress Field Distribution}

In this research, two kinds of research schemes were set up, with each containing three kinds of excavation scheme. The first kind of scheme is the excavation of one tunnel at a time, and the second is a simultaneous double-hole excavation. The distance between the excavation of different batches of pilot tunnels was staggered by $20 \mathrm{~m}$. All schemes were named using the aforementioned pilot tunnel numbers. For example, excavation scheme 1 of the first kind relates to the excavation in the following sequence: tunnel numbers 2, 3 , $1,4,6,7,5$, and 8, denoted as S-2-3-1-4-6-7-5-8 for convenience. In this code, $S$ means the first excavation scheme, excavation of one tunnel at a time, and the numbers represent the pilot tunnel numbers according to the excavation sequence. Excavation scheme 1 of the second kind relates to the excavation in the following sequence: tunnel numbers 2 and 3, 1 and 4, 6 and 7, and 5 and 8, denoted as D-23-14-67-58. In this code, D means a 
simultaneous double-hole excavation, and the numbers represent the pilot tunnel numbers according to the excavation sequence. Using the above code, this research analyses the following schemes: S-2-3-1-4-6-7-5-8 (Scheme 1), S-1-4-2-3-5-8-6-7 (Scheme 2), S-1-3-2-4-57-6-8 (Scheme 3), D-23-14-67-58 (Scheme 4), D-14-23-58-67 (Scheme 5), and D-13-24-57-68 (Scheme 6).

\subsection{Simulation Results of the First Kind of Scheme (Schemes 1 to 3)}

The vertical stress at each monitoring point was obtained using numerical simulations; then, the stress field distributions were visualized and these are presented in Figures 5-7. In these figures, the $\mathrm{x}$ coordinate represents the longitudinal dimension from the tunnel entrance, the y coordinate represents the horizontal distance from any point to the center of station, and the $\mathrm{z}$ coordinate represents the vertical stress. Vertical stress over $30 \mathrm{~m}$ from both sides of the station centerline retained its initial value, which means that the stress distribution was not affected by the excavation of pilot tunnels. Therefore, the stress field distribution only has a range from $y=-30 \mathrm{~m}$ to $\mathrm{y}=30 \mathrm{~m}$. The effect of pilot tunnel excavation on vertical stress has a range that is essentially equal to twice the width of the station, considering an excavation scope from $\mathrm{y}=-16.5 \mathrm{~m}$ to $\mathrm{y}=16.5 \mathrm{~m}$. Therefore, the effects of construction on the surrounding environment and buildings in this area must be considered during construction.

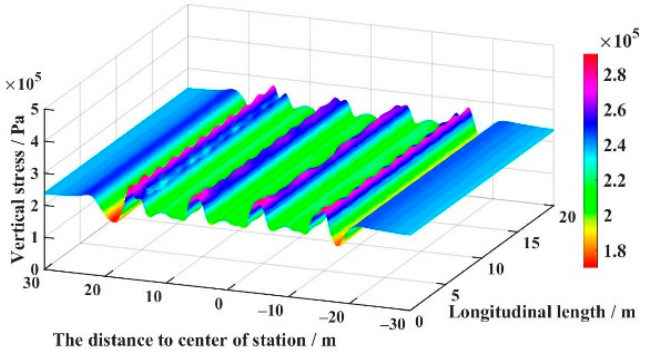

(a)

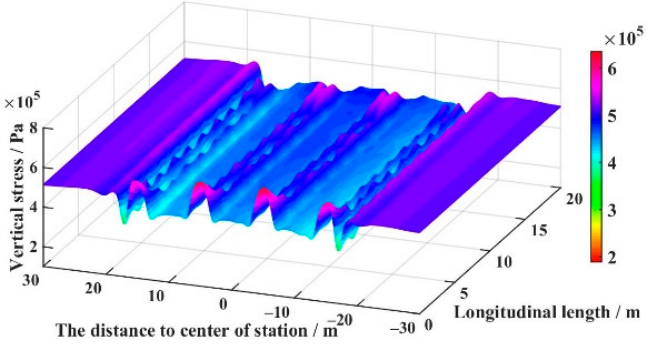

(c)

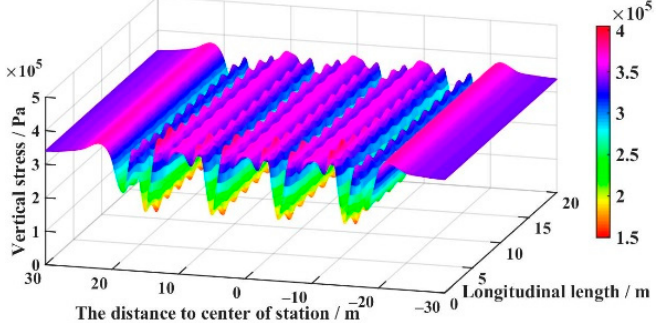

(b)

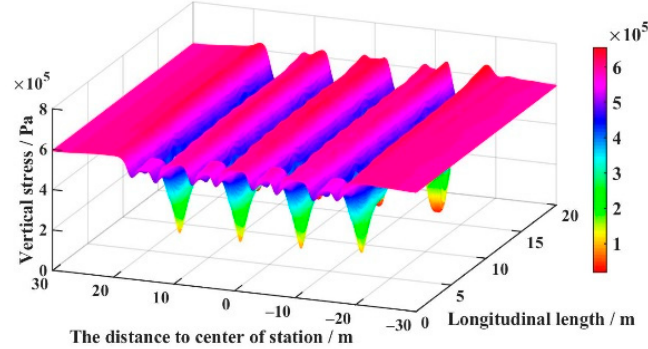

(d)

Figure 5. Stress fields of scheme 1 (S-2-3-1-4-6-7-5-8): (a) P1 $(\mathrm{z}=4.5 \mathrm{~m}),($ b) P2 ( $\mathrm{z}=0 \mathrm{~m})$, (c) P3 $(\mathrm{z}=-8.3 \mathrm{~m})$, and $(\mathrm{d})$ P4 $(\mathrm{z}=-12.8 \mathrm{~m})$.

As seen in Figure 5, the stress distribution on each monitoring plane has significant peaks and valleys, wherein the distribution of peaks and valleys, or maximum stress on each plane is different.

On the plane P1 $(\mathrm{z}=4.5 \mathrm{~m})$, the peaks are mainly distributed where pilot tunnels are located and the valleys between pilot tunnels are relatively gentle. Additionally, with increasing distance to the center of the station, the valleys far from the sides of the pilot tunnels are significant, indistinctive peaks also appear far from the sides, and the stress in these areas is relatively normal. The average vertical stress in unaffected regions is $232.7 \mathrm{kPa}$, and the maximum vertical stress in affected regions is $291.7 \mathrm{kPa}$. A stress concentration factor needs to be defined for comparison of different schemes, and its value is equal to the maximum vertical stress occurring in the monitoring plane divided by the average vertical stress in the soil at this location before the tunnel is excavated; that is, divided by 
the average vertical stress in unaffected regions. Therefore, the stress concentration factor is 1.254 . The extreme point is located at $(2,16,4.5)$, which is above pilot tunnel 1 .

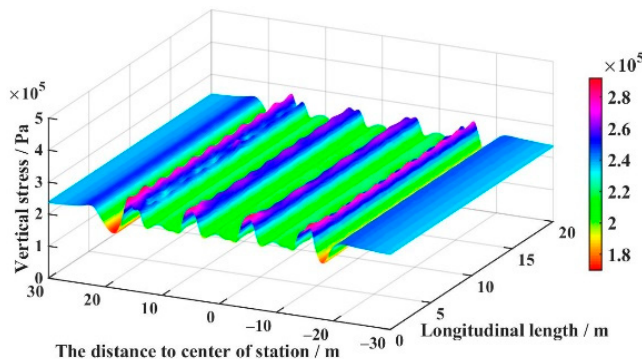

(a)

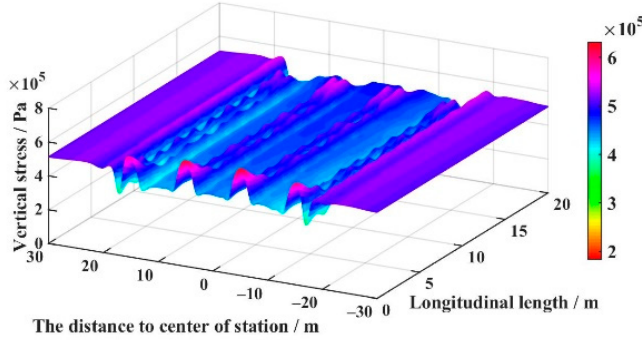

(c)

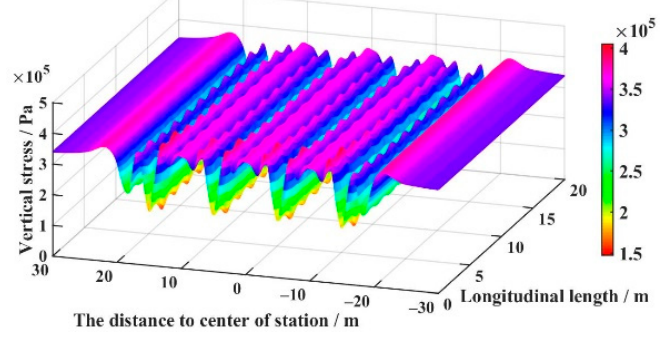

(b)

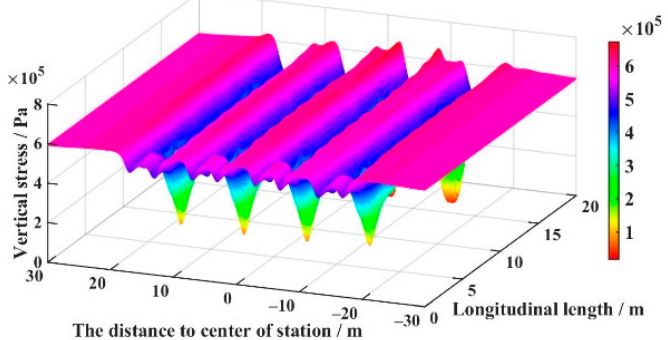

(d)

Figure 6. Stress fields of scheme 2 (S-1-4-2-3-5-8-6-7): (a) P1 $(\mathrm{z}=4.5 \mathrm{~m}),(\mathbf{b}) \mathrm{P} 2(\mathrm{z}=0 \mathrm{~m})$, (c) P3 $(z=-8.3 \mathrm{~m})$, and (d) P4 $(\mathrm{z}=-12.8 \mathrm{~m})$.

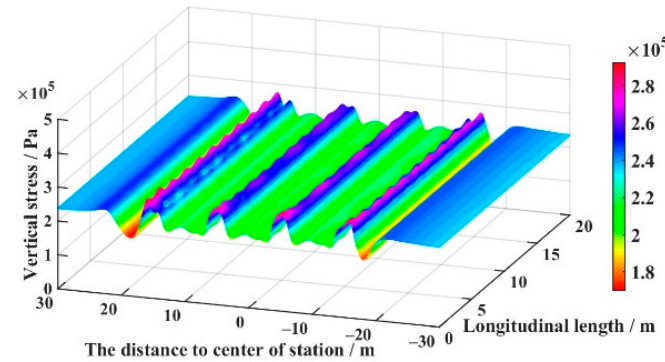

(a)

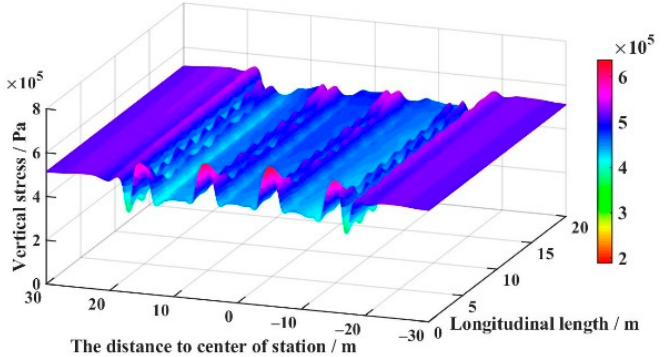

(c)

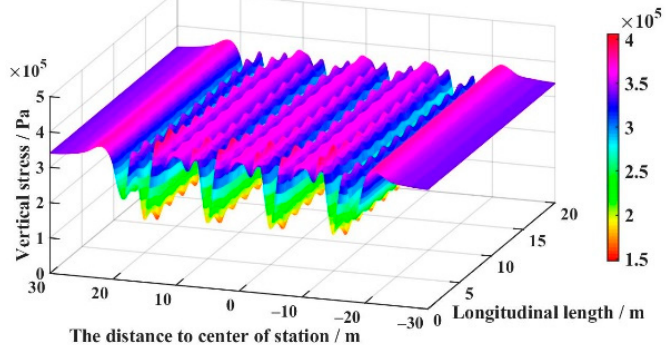

(b)

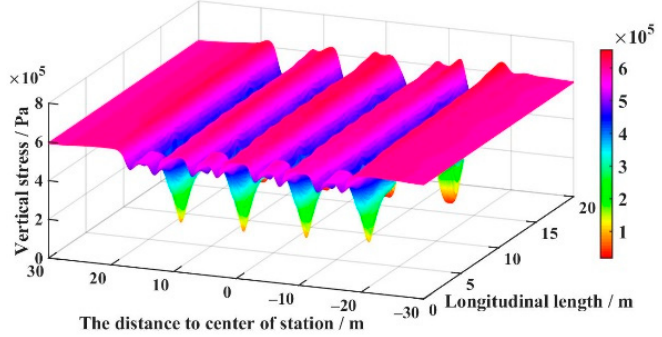

(d)

Figure 7. Stress fields of scheme 3 (S-1-3-2-4-5-7-6-8): (a) P1 $(\mathrm{z}=4.5 \mathrm{~m})$, (b) P2 (z=0 m), (c) P3 $(\mathrm{z}=-8.3 \mathrm{~m})$, and $(\mathrm{d})$ P4 $(\mathrm{z}=-12.8 \mathrm{~m})$.

On the plane P2 $(\mathrm{z}=0 \mathrm{~m})$, the valleys are mainly distributed where the pilot tunnels are located and peaks can be found on both sides of any pilot tunnel. The average vertical stress in unaffected regions is $334.3 \mathrm{kPa}$, and the maximum vertical stress in affected regions is $404.8 \mathrm{kPa}$. The stress concentration factor is 1.211 . The extreme point is located at $(2,13,0)$, which is between pilot tunnels 1 and 2 .

The distribution law of a stress field on the plane P3 $(z=-8.3 \mathrm{~m})$ is similar to that on the plane $\mathrm{P} 1$, but the differences are that the peaks between pilot tunnels are more 
significant and the outermost peaks are found on both sides. The average vertical stress in unaffected regions is $502.2 \mathrm{kPa}$, and the maximum vertical stress in affected regions is $634.8 \mathrm{kPa}$. The stress concentration factor is 1.264 . The extreme point is located at $(0,-5,-8.3)$, which is in the middle, above pilot tunnel 7 .

The distribution law of a stress field on the plane P4 $(\mathrm{z}=-12.8 \mathrm{~m})$ is similar to that on the plane P2, but the difference is that the peaks are not significant compared with those in the plane P2. The average vertical stress in unaffected regions is $582.5 \mathrm{kPa}$, and the maximum vertical stress in affected regions is $644.4 \mathrm{kPa}$. The stress concentration factor is 1.106. The extreme point is located at $(20,-12,-12.8)$, which is between pilot tunnels 7 and 8 .

Figure 6 shows the stress field distribution for scheme 2 (S-1-4-2-3-5-8-6-7). The distribution laws of stress on the four monitoring planes are similar to those of scheme 1. The specific results are as follows.

On the plane P1 $(\mathrm{z}=4.5 \mathrm{~m})$, the maximum vertical stress in affected regions is $292.1 \mathrm{kPa}$ and the stress concentration factor is 1.255 . The extreme point is located at $(2,16,4.5)$, which is same as in scheme 1.

On the plane P2 $(\mathrm{z}=0 \mathrm{~m})$, the maximum vertical stress in affected regions is $405.5 \mathrm{kPa}$ and the stress concentration factor is 1.213 . The extreme point is located at $(2,-13,0)$, which is between pilot tunnels 3 and 4 .

On the plane P3 $(\mathrm{z}=-8.3 \mathrm{~m})$, the maximum vertical stress in affected regions is $631.2 \mathrm{kPa}$ and the stress concentration factor is 1.257. The extreme point is located at $(0,-5,-8.3)$, which is same as in scheme 1 .

On the plane P4 $(\mathrm{z}=-12.8 \mathrm{~m})$, the maximum vertical stress in affected regions is $669.0 \mathrm{kPa}$ and the stress concentration factor is 1.148 . The extreme point is located at $(20,-2,-12.8)$, which is between pilot tunnels 6 and 7 but closer to pilot tunnel 7 .

Comparing scheme 1 with scheme 2 , a certain level of difference in the stress concentration factor can be found between P3 and P4, and the extreme points for P2 and P4 are also different.

Figure 7 shows the stress field distribution of scheme 3 (S-1-3-2-4-5-7-6-8). The distribution laws of stress on the four monitoring planes are similar to those of schemes 1 and 2 . The specific results are as follows.

On the plane P1, the maximum vertical stress in affected regions is $292.4 \mathrm{kPa}$ and the stress concentration factor is 1.255 . On the plane P2, the maximum vertical stress in affected regions is $405.9 \mathrm{kPa}$ and the stress concentration factor is 1.214 . On the plane P3, the maximum vertical stress in affected regions is $636.1 \mathrm{kPa}$ and the stress concentration factor is 1.267 . On the plane $\mathrm{P} 4$, the maximum vertical stress in affected regions is $643.8 \mathrm{kPa}$ and the stress concentration factor is 1.105 . The extreme points of each plane are located at the same coordinates as those in scheme 1.

Compared with schemes 1 and 2, the results of scheme 3 are closer to those of scheme 1 .

\subsection{Simulation Results of the Second Kind of Scheme (Schemes 4 to 6)}

Schemes 4-6 adopt the same method used in Section 4.1 to simulate simultaneous excavation of two pilot tunnels. The results show that the distribution laws of different monitoring planes are the same as those of schemes 1-3 accordingly. Therefore, this section does not present all of the stress field distributions but rather only specific simulation results.

(1) Scheme 4 (D-23-14-67-58)

The maximum vertical stresses in affected regions on planes $\mathrm{P} 1$ to $\mathrm{P} 4$ are $291.7 \mathrm{kPa}$, $405.0 \mathrm{kPa}, 632.9 \mathrm{kPa}$, and $643.0 \mathrm{kPa}$, respectively. Accordingly, the stress concentration factors on planes P1 to P4 are 1.254,1.211, 1.260, and 1.104, respectively. The extreme points on planes P1 to P3 are located at the same coordinates as those in scheme 1 and that on the plane P4 is located at $(20,12,-12.8)$, which is between pilot tunnels 5 and 6 .

(2) Scheme 5 (D-14-23-58-67) 
On planes P1 to P4, the maximum vertical stresses in affected regions are $292.1 \mathrm{kPa}$, $404.2 \mathrm{kPa}, 631.6 \mathrm{kPa}$, and $666.0 \mathrm{kPa}$, respectively. Accordingly, the stress concentration factors are $1.255,1.209,1.258$, and 1.143 , respectively. The extreme points on planes P1 to P3 are located at the same coordinates as those in scheme 1 , and that on the plane P4 is located at $(20,2,-12.8)$, which is between pilot tunnels 6 and 7 but closer to pilot tunnel 6 .

\section{(3) Scheme $6(\mathrm{D}-13-24-57-68)$}

On the plane P1, the maximum vertical stress in affected regions is $291.6 \mathrm{kPa}$, the stress concentration factor is 1.253 , and the extreme point is located at the same coordinate as that in scheme 1 . On the plane P2, the maximum vertical stress is $403.7 \mathrm{kPa}$, the stress concentration factor is 1.208 , and the extreme point is located at the same coordinate as that in scheme 1 . On the plane P3, the maximum vertical stress in affected regions is $726.9 \mathrm{kPa}$; the stress concentration factor is 1.447; and the extreme point is located at $(10,5,-8.3)$, which is above the longitudinal middle, where pilot tunnel 6 is located. Compared with scheme 3, the extreme value found on the plane P3 significantly improves, and the stress field distribution of this plane is as shown in Figure 8. Peaks appear in the longitudinal middle of pilot tunnels 6 and 8. On the plane P4, the maximum vertical stress in affected regions is $666.5 \mathrm{kPa}$ and the stress concentration factor is 1.144 . The extreme point is located at $(20,2,-12.8)$, which is same as that in scheme 5 .

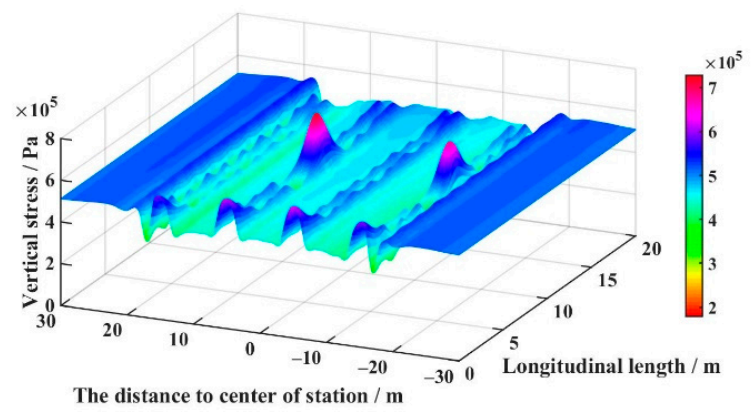

Figure 8. Stress fields of scheme 6 (D-13-24-57-68) on the plane P3.

A summary of the results of schemes 1 to 6 is presented in Table 2. The table shows that the stress concentration factors on planes P1 and P2 of all schemes are almost the same but those on planes P3 and P4 have significant differences. The stress concentration factors of pilot tunnels located at the bottom of the group are significantly affected by the excavation sequence. Scheme 6 leads to a relatively higher concentration factor on the plane P3, and schemes 2, 5, and 6 cause the concentration factors to be slightly higher than the other three on the plane P4. After comprehensive consideration, the stress concentration factor of scheme 4 is relatively small, and its construction efficiency is high due to the scheme being a simultaneous double-hole excavation.

Table 2. Stress concentration factors for schemes 1 to 6 on each monitoring plane.

\begin{tabular}{ccccc}
\hline \multirow{2}{*}{ Scheme } & \multicolumn{4}{c}{ Stress Concentration Factor } \\
\cline { 2 - 5 } & P1 & P2 & P3 & P4 \\
\hline Scheme 1 (S-2-3-1-4-6-7-5-8) & 1.254 & 1.211 & 1.264 & 1.106 \\
Scheme 2 (S-1-4-2-3-5-8-6-7) & 1.255 & 1.213 & 1.257 & 1.148 \\
Scheme 3 (S-1-3-2-4-5-7-6-8) & 1.255 & 1.214 & 1.267 & 1.105 \\
Scheme 4 (D-23-14-67-58) & 1.254 & 1.211 & 1.260 & 1.104 \\
Scheme 5 (D-14-23-58-67) & 1.255 & 1.209 & 1.258 & 1.143 \\
\hline
\end{tabular}

Table 3 shows the extreme points of different monitoring planes under different schemes. As can be seen, the results of the plane P1 are exactly the same, and only one scheme is different for both planes P2 and P3. Comparatively, some differences are found 
on the plane P4. A similar phenomenon is seen in the stress concentration factors: the pilot tunnels located at the top of the group are less affected by the excavation sequence than the lower tunnels. The extreme point on the plane P4 is most significantly affected by the excavation sequence.

Table 3. The extreme points of Schemes 1 to 6.

\begin{tabular}{ccccc}
\hline \multirow{2}{*}{ Scheme } & \multicolumn{4}{c}{ Coordinates of the Extreme Points } \\
\cline { 2 - 5 } & P1 & P2 & P3 & P4 \\
\hline Scheme 1 (S-2-3-1-4-6-7-5-8) & $(2,16,4.5)$ & $(2,13,0)$ & $(0,-5,-8.3)$ & $(20,-12,-12.8)$ \\
Scheme 2 (S-1-4-2-3-5-8-6-7) & $(2,16,4.5)$ & $(2,-13,0)$ & $(0,-5,-8.3)$ & $(20,-2,-12.8)$ \\
Scheme 3 (S-1-3-2-4-5-7-6-8) & $(2,16,4.5)$ & $(2,13,0)$ & $(0,-5,-8.3)$ & $(20,-12,-12.8)$ \\
Scheme 4 (D-23-14-67-58) & $(2,16,4.5)$ & $(2,13,0)$ & $(0,-5,-8.3)$ & $(20,12,-12.8)$ \\
Scheme 5 (D-14-23-58-67) & $(2,16,4.5)$ & $(2,13,0)$ & $(0,-5,-8.3)$ & $(20,2,-12.8)$ \\
Scheme 6 (D-13-24-57-68) & $(2,16,4.5)$ & $(2,13,0)$ & $(10,5,-8.3)$ & $(20,2,-12.8)$ \\
\hline
\end{tabular}

\section{Study on the Formation of the Stress Field}

Point $(0,-5,-8.3)$ of the plane P3 was selected as a representative monitoring point; this is the extreme point for schemes 1 to 5 , located in the middle above pilot tunnel 7 . After processing the monitoring data, the stress curves for this point in schemes 1 to 6 were drawn, as shown in Figure 9. All six curves show stress during the excavation of pilot tunnel 7, which is in accordance with common sense that the surrounding rock stress decreases after tunnel excavation. However, with stress redistribution around the tunnel, the stress at each monitoring point gradually increases. The stress curves change at the same time, during the excavation of pilot tunnel 7 in schemes $1,3,4$, and 6 . The excavation of pilot tunnel 7 in schemes 2 and 5 lags behind a little, so stress accumulates faster at a later period.

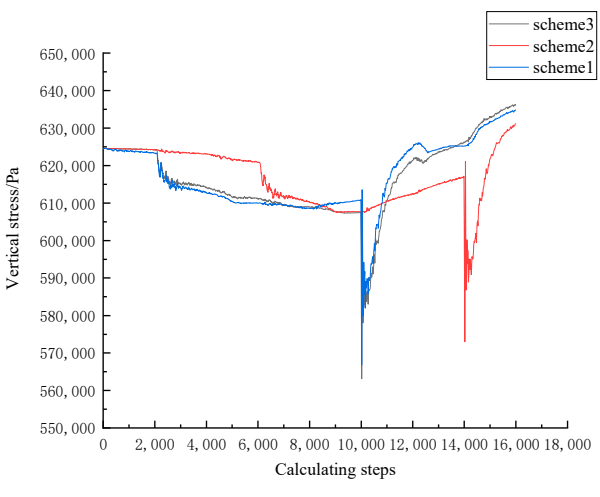

(a)

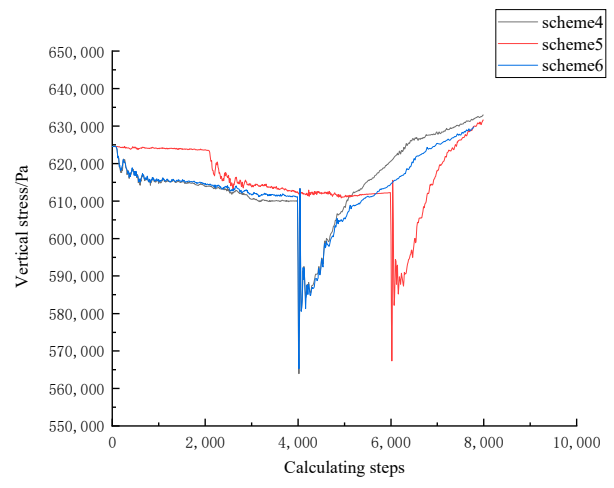

(b)

Figure 9. Stress curves of representative monitoring points: (a) schemes 1 to 3 and (b) schemes 4 to 6 .

To further study the formation of a stress field, the plane P3 of schemes 3 and 6 was selected as the object of research considering that stress concentration factors have a larger difference. Therefore, stress field distribution diagrams were drawn at this stage according to the construction sequence, as shown in Figure 10, and the differences between the stress field formation processes between two schemes were studied.

As can be seen from the figure, different distributions in the stress fields occur on the plane P3 when using different excavation schemes. During excavation, the distributions in the stress fields during the first three excavation steps are almost the same. However, after the fourth step, stress significantly concentrates in the central part of the plane P3, which is caused by the excavations of pilot tunnels 6 and 8 . Different excavation schemes have different impacts on the last step of construction, with some being greater; therefore, when 
excavating pilot tunnels 6 and 8 , scheme 3 is the better choice for reducing the influence of stress concentration on the soil around pilot tunnels. If scheme 6 is used, supports must be constructed in a timely manner.

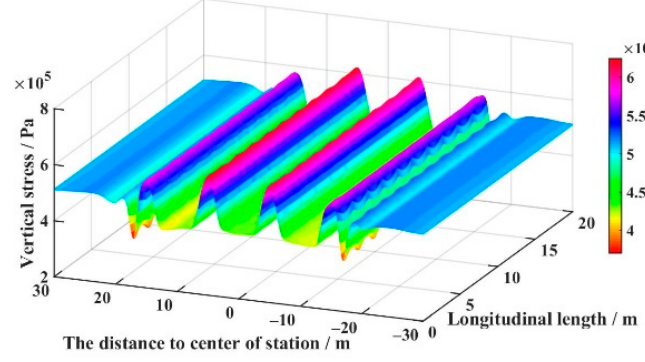

(a)

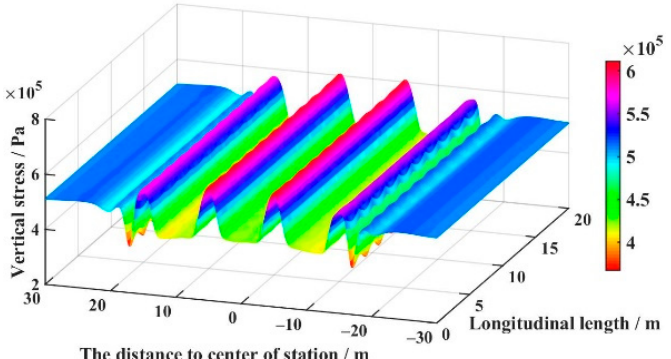

(b)

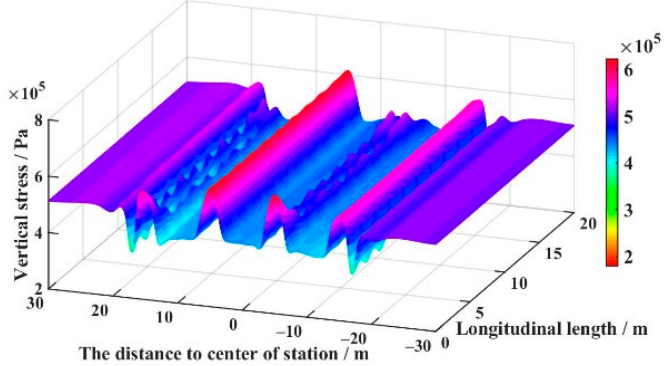

(c)

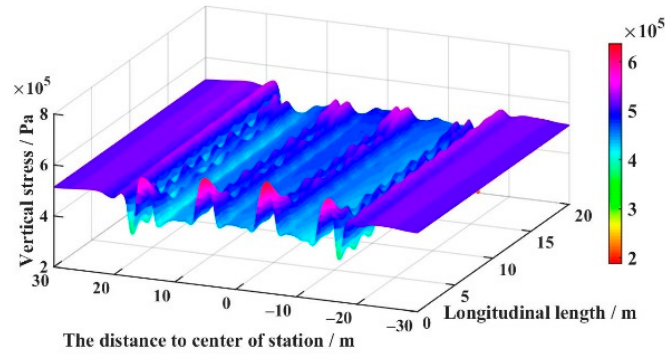

(d)

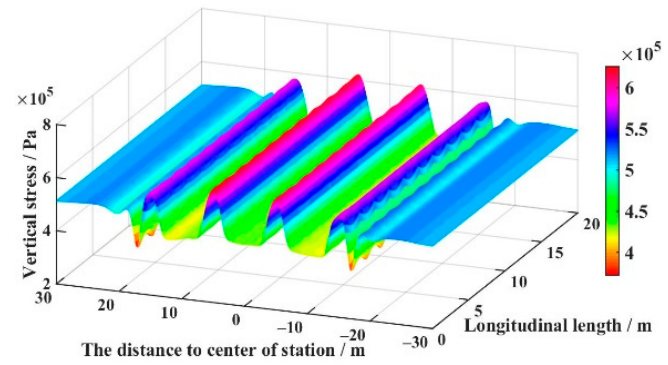

(e)

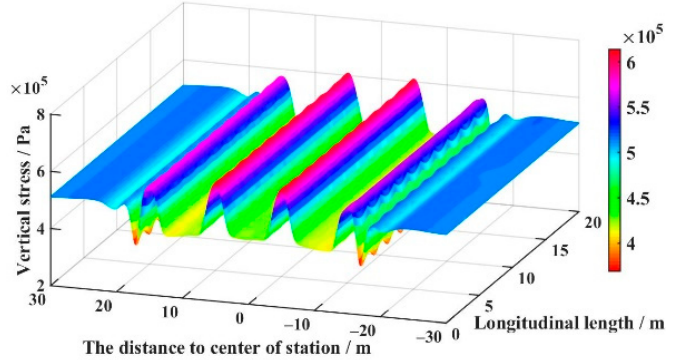

(f)

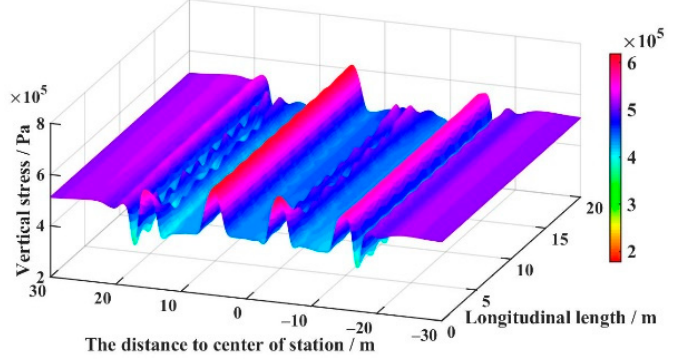

(g)

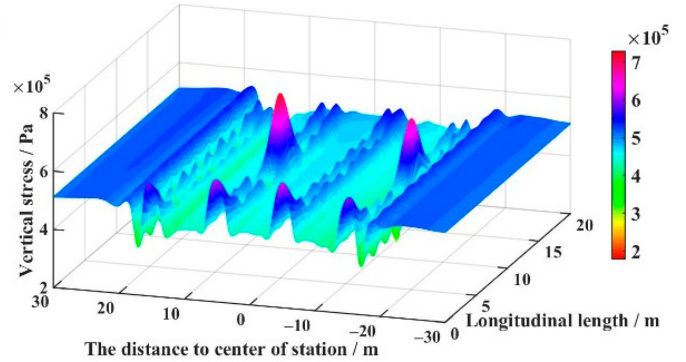

(h)

Figure 10. Formation processes of the stress fields in schemes 3 and 6: (a) 1-3, (b) 1-3-2-4, (c) 1-3-2-45-7, (d) 1-3-2-4-5-7-6-8, (e) 13, (f) 13-24, (g) 13-24-57, and (h) 13-24-57-68.

Figure 11 gives the vertical stress contour of the $x=10 \mathrm{~m}$ section of scheme 3 . The distributions of other schemes are similar and, therefore, are not given here. As can be found, a significant stress relief area appears below the pilot tunnels after excavation, and the high stress area on both sides extends upward. This stress leads to the plane P2 releasing its stress below the pilot tunnels and increases the amount of stress between the bottoms of the tunnels. The vertical stress at the top of the pilot tunnels is higher than that in outer areas, and the low stress area between the tops of the pilot tunnels extends downward. This leads to the amount of stress on the plane P1 increasing at the tops of the pilot tunnels 
and releasing between the tops of the tunnels. Additionally, planes P3 and P4 show the same pattern.

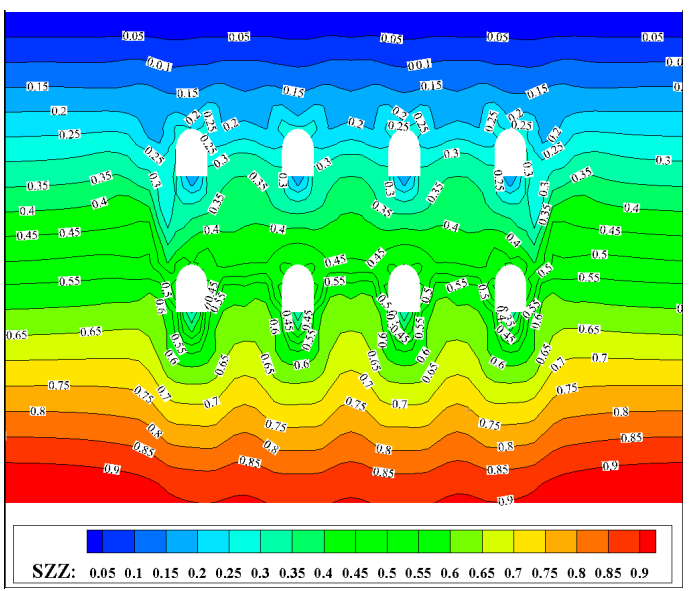

Figure 11. Vertical stress contour (section $x=10 \mathrm{~m})$.

\section{Model Verification}

To further validate the previous simulation results, a physical model of the underground pilot tunnels for this subway station was built in a laboratory. Considering the convenience of testing and the limitations in the size of the test instrument, the ratio of similarity between this model and the actual scenario was obtained based on similarity theory and multiple proportioning tests and is shown in Table 4. This test mainly involved five similarity ratios; namely, geometric similarity ratio, gravity similarity ratio, acceleration similarity ratio, stress similarity ratio, and force similarity ratio. They all represent the ratio of the corresponding prototype's physical quantity to the model's physical quantity, and the definition of each parameter is shown in Table 4. Considering the equipment size and the convenience of research, the geometric similarity ratio was set as 30 . The unit weight similarity ratio was preliminarily determined as 1.1 and then corrected by the test to be 0.87 . The acceleration similarity ratio was taken as 1 due to the same self-weight stress field. The stress similarity ratio and force similarity ratio were converted by the formula in Table 4 . The size of the prototype pilot tunnel is $3.5 \mathrm{~m}$ wide and $4.25 \mathrm{~m}$ high, and the size of the model pilot tunnel is $116.6 \mathrm{~mm}$ wide and $141.7 \mathrm{~mm}$ high according to this similarity ratio, as shown in Figure 12. The physical model has a width of $1200 \mathrm{~mm}$, a height of $900 \mathrm{~mm}$, and a longitudinal dimension of $150 \mathrm{~mm}$.

Table 4. Similarity ratio.

\begin{tabular}{ccc}
\hline Similarity Ratio Items & Definition formulas & Values \\
\hline Geometric similarity ratio $C_{L}$ & $C_{L}=\frac{L_{P}}{L_{M}}$ & 30 \\
Unit weight similarity ratio $C_{\gamma}$ & $C_{\gamma}=\frac{\gamma P}{\gamma_{M}}$ & 0.87 \\
Acceleration similarity ratio $C_{a}$ & $C_{a}=\frac{a_{P}}{a_{M}}$ & 1 \\
Stress similarity ratio $C_{\sigma}$ & $C_{\sigma}=\frac{\sigma_{P}}{\sigma_{M}}=C_{L} \times C_{\gamma}$ & 26.1 \\
Force similarity ratio $C_{F}$ & $C_{F}=\frac{F_{P}}{F_{M}}=C_{L}^{3} \times C_{\gamma}$ & 23,490 \\
\hline
\end{tabular}

Note: $L_{P}, \gamma_{P}, a_{P}, \sigma_{P}, F_{P}$ are the dimension, unit weight, acceleration, stress, and force in the tunnel and soil, respectively; $L_{M}, \gamma_{M}, a_{M}, \sigma_{M}, F_{M}$ are the dimension, unit weight, acceleration, stress, and force in the model, respectively.

According to the similarity ratio determined above, finding suitably similar materials is necessary. This test mainly involves simulating the soil layer and primary support, in which the primary support includes a grid steel frame and shotcrete. As the main purpose of this model was to study the change law for internal stress in the soil around the pilot tunnel and not to pursue a high degree of consistency with the results of the numerical simulation, the soil composition was simplified in this model and the same homogeneous 
soil layer was used, which reduced the workload of the model and avoided influence from soil filling errors.

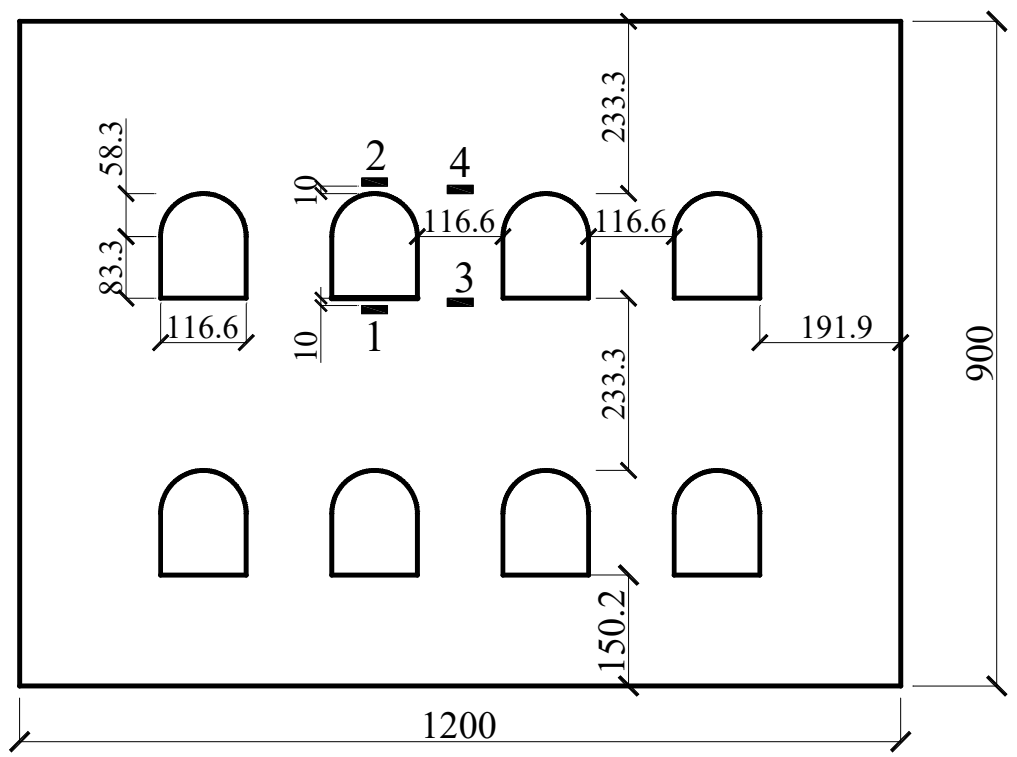

Figure 12. Stress monitoring points (unit: $\mathrm{mm}$ ).

Through the proportioning test shown in Figure 13, a similar material with a mass ratio of river sand to gypsum of 20:1 was finally selected to simulate the soil mass through a direct shear test; a similar material with a ratio of river sand to cement of 15:5 was selected to simulate the shotcrete through a compressive strength test; and a $0.8 \mathrm{~mm}$ tin wire was selected to simulate reinforcement through the tensile strength test. After the materials for the model were selected, the corresponding strata and primary support models were made, as shown in Figure 14. In order to ensure the accuracy of the model test, the time interval from the making of the model to the start of the test should be consistent with the age of the sample for the proportioning test.

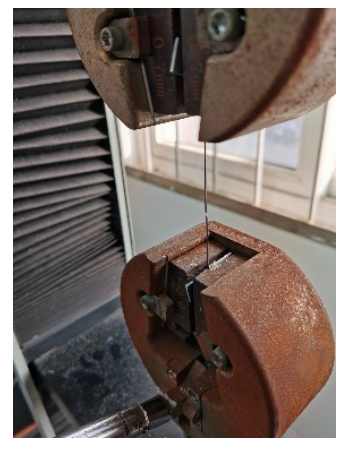

(a)

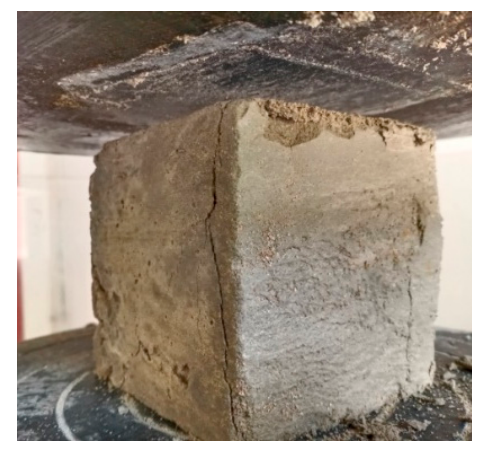

(b)

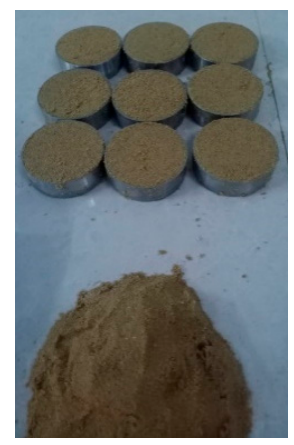

(c)

Figure 13. Proportioning tests: (a) breaking force test, (b) compressive strength test, and (c) direct shear test.

To compare the changes in soil stress around pilot tunnels, four earth pressure cells were set up in the model, as shown in Figure 12. The dimensions of the model, the sizes of the pilot tunnels, and the locations of the stress monitoring points are also given in the figure. In the test, the sensitivity coefficient of the earth pressure cell was about $0.5 \mathrm{kPa} / \mu \varepsilon$, and the accuracy error was less than or equal to $0.5 \% \mathrm{~F}$. S. The test was carried out with a static resistance strain gauge. The strain gauge model was XL2118A, and the sampling interval was set as $0.2 \mathrm{~s}$ in the test. 


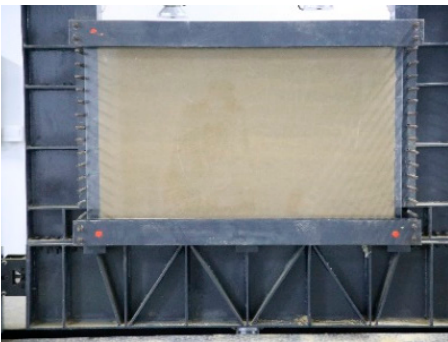

(a)

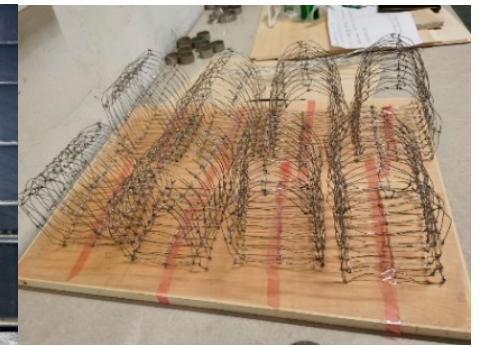

(b)

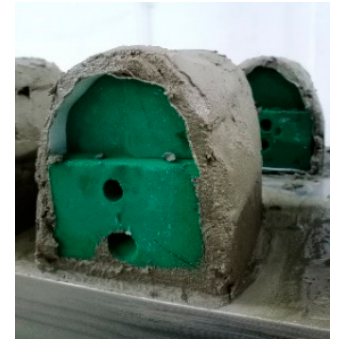

(c)

Figure 14. Model making: (a) model soil, (b) grid steel frame model, and (c) primary support.

During the test, pilot tunnels were excavated one by one in the following order: 57-6-8-1-3-4-2, as shown in Figure 15. Excavating in this order mainly considers that the construction sequence had little effect on the stress distribution laws in the previous study and ensures the stability of model during excavation.

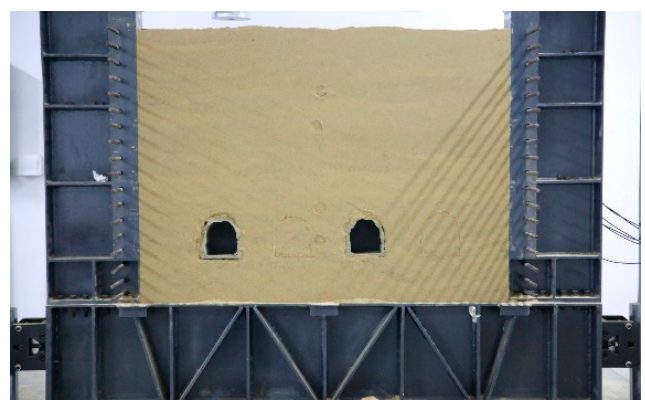

(a)

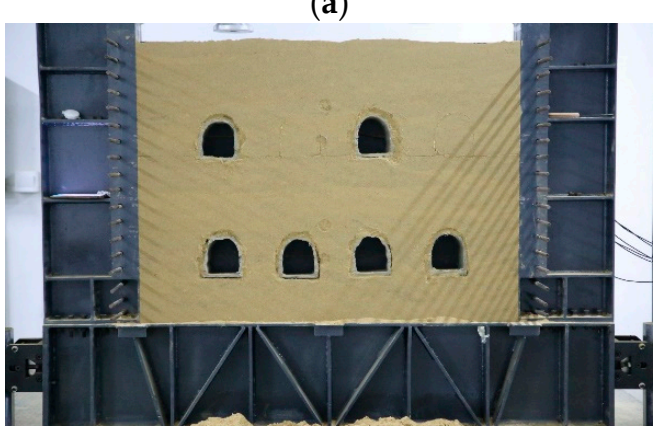

(c)

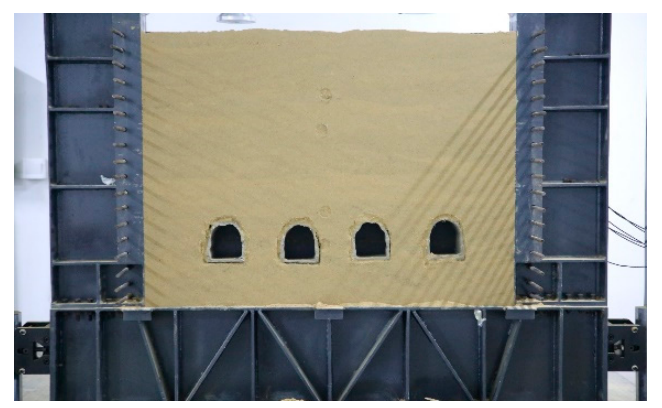

(b)

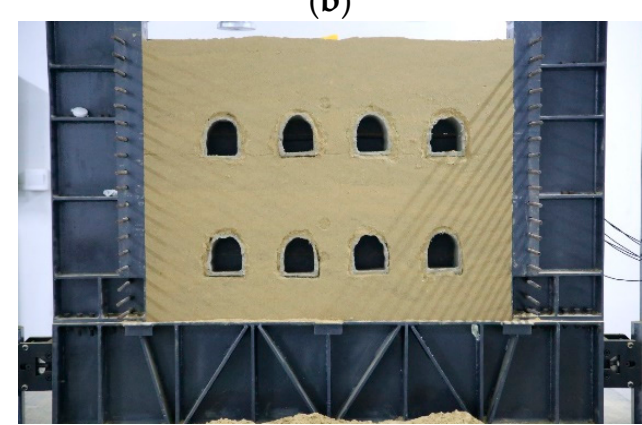

(d)

Figure 15. Excavation of the pilot tunnels: (a) 5-7; (b) 5-7-6-8; (c) 5-7-6-8-1-3 and (d) 5-7-6-8-1-3-4-2.

Figure 16 gives the stress increments of the four monitoring points, with the abscissa representing the number of stress-monitoring points in this figure. As seen in this figure, when all pilot tunnels are excavated, the vertical stresses at monitoring points 1 and 4 are reduced to $6.49 \mathrm{kPa}$ and $0.53 \mathrm{kPa}$, respectively, but at monitoring points 2 and 3 , there are increases to $3.62 \mathrm{kPa}$ and $4.00 \mathrm{kPa}$, respectively. This situation is largely consistent with the results of the numerical simulation, where the peaks are mainly distributed both at the tops of the pilot tunnels and between the bottoms of tunnels and where valleys are mainly distributed both at the bottoms of pilot tunnels and between the tops of tunnels. 


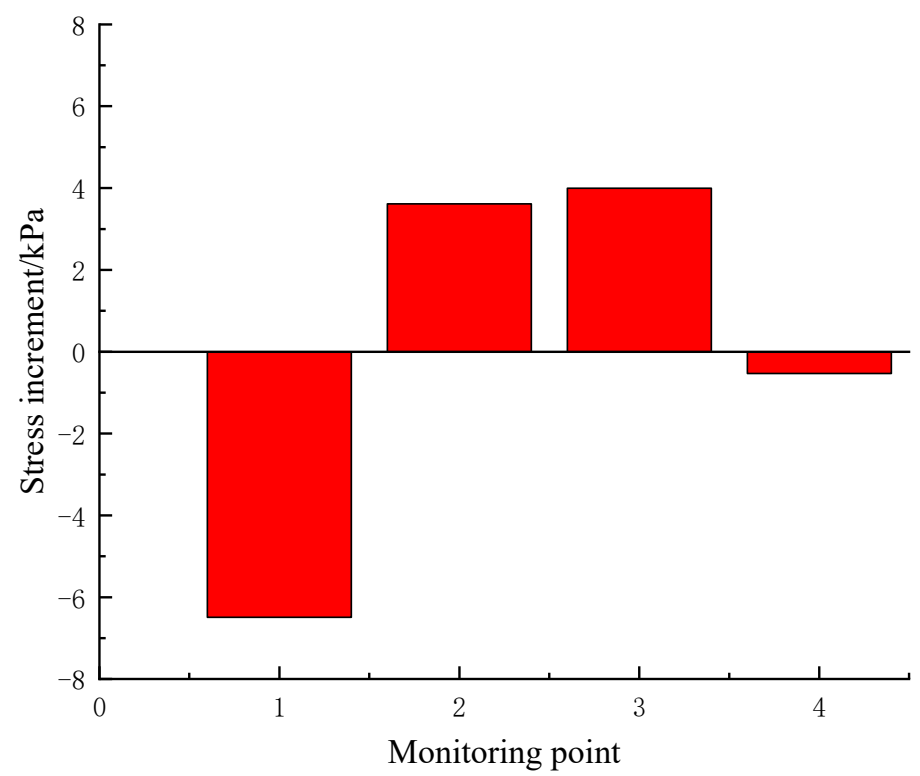

Figure 16. Stress increment of the monitoring points.

\section{Conclusions}

a. The vertical stress in the area beyond $30 \mathrm{~m}$ on both sides of the station, which is the centerline, was not affected by the excavation of pilot tunnels; therefore, the effect of the excavation of pilot tunnels on vertical stress has a range that is essentially equal to twice the width of the station. Therefore, the effects of construction on the surrounding environment and buildings must be considered during construction.

b. After the excavation of pilot tunnels, peaks appeared both at the tops of the pilot tunnels and between the bottoms of the tunnels and valleys appeared both at the bottoms of the pilot tunnels and between the tops of the tunnels. Furthermore, the stress concentration factor on the plane P3 was higher than that on the plane P1, and that on the plane P2 was higher than that on the plane P4.

c. The stress concentration factors on planes P1 and P2 of all schemes were almost the same after construction, but those on planes $\mathrm{P} 3$ and $\mathrm{P} 4$ had significant differences. Therefore, the stress concentration factor from pilot tunnels located at the bottom of the group are significantly affected by the excavation sequence.

d. Comparing the extreme points of the different schemes, those on the plane P1 are exactly the same, and only one scheme has a different extreme point among schemes on planes P2 and P3. Comparatively, some differences were found on the plane P4. A similar phenomenon was seen in the results of the stress concentration factor: the pilot tunnels located at the top of the group were less affected by the excavation sequence than the lower tunnels. The extreme point on the plane P4 was most significantly affected by the excavation sequence.

e. In the model, the stress-monitoring results show that the stress at each monitoring point increases at both the tops of the pilot tunnels and between the bottoms of the tunnels, while it decreases at both the bottoms of the pilot tunnels and between the tops of the tunnels. Therefore, the model verified the numerical simulation results of the stress variation law.

Although some meaningful research results have been obtained in this study, there are still some shortcomings; for example, due to the limitation of experimental instruments, the longitudinal dimension of the physical model was less than that of the numerical model, and only the stress variation law of the measuring points could be mutually verified; only four monitoring planes were selected, which could not fully reflect the stress field within the station. In future research, more accurate subway engineering model technology can be considered, in order to provide more accurate experimental reference for construction 
units before the implementation of the actual project. Furthermore, the distribution of the stress field after freezing can be studied. Under the background that the freezing method is increasingly used in the construction of subway stations, the influence of freezing on the internal force of temporary support and the stress field of the soil layer can be analyzed by experiments.

Author Contributions: Conceptualization, B.H. and Y.D.; software, Y.Z. (Yu Zeng); validation, B.H., Y.Z. (Yu Zou) and Q.Y.; investigation, Y.D.; data curation, B.H. and Y.Z. (Yu Zou); writing-original draft preparation, B.H.; writing-review and editing, B.H., Y.Z. (Yu Zeng) and Y.D.; visualization, B.C. All authors have read and agreed to the published version of the manuscript.

Funding: This research was funded by the Natural Science Research Project of Colleges and Universities in Anhui Province, grant No. KJ2018A0118 and No. KJ2020A0366; by the Scientific Research Project of Anhui Polytechnic University, grant No. Xjky110201912; by the National Innovation and Entrepreneurship Training Project for College Students, grant No. 202010363117; and by the National Natural Science Fund Pre Project of Anhui Polytechnic University, grant No. 2019yyzr08.

Institutional Review Board Statement: Not applicable.

Informed Consent Statement: Not applicable.

Data Availability Statement: Not applicable.

Conflicts of Interest: The authors declare no conflict of interest.

\section{References}

1. Liu, W.; Luo, F.; Mei, J. A new construction method for a metro station in Beijing. Tunn. Undergr. Space Technol. 2000, 15, 409-413. [CrossRef]

2. Fang, Q.; Zhang, D.; Wong, L.N.Y. Shallow tunneling method (STM) for subway station construction in soft ground. Tunn. Undergr. Space Technol. 2012, 29, 10-30. [CrossRef]

3. Ocak, I. Control of surface settlements with umbrella arch method in second stage excavations of Istanbul Metro. Tunn. Undergr. Space Technol. 2008, 23, 674-681. [CrossRef]

4. Chakeri, H.; Ozcelik, Y.; Unver, B. Effects of important factors on surface settlement prediction for metro tunnel excavated by EPB. Tunn. Undergr. Space Technol. 2013, 36, 14-23. [CrossRef]

5. Sirivachiraporn, A.; Phienwej, N. Ground movements in EPB shield tunneling of Bangkok subway project and impacts on adjacent buildings. Tunn. Undergr. Space Technol. 2012, 30, 10-24. [CrossRef]

6. Weng, W. Study on Falsework about PBA Method in Underground Passage. J. Hunan City Univ. (Nat. Sci.) 2011, 20, 14-16. [CrossRef]

7. Li, B.; Wang, Z. Numerical study on the response of ground movements to construction activities of a metro station using the pile-beam-arch method. Tunn. Undergr. Space Technol. 2019, 88, 209-220. [CrossRef]

8. Huang, R. PBA Method Applied in the Construction of Arch in Subway Station. Chin. J. Undergr. Space Eng. 2007, 2, 268-271. [CrossRef]

9. Li, X. Numerical Simulation on PBA Job Practice of Metro Station. Chin. J. Undergr. Space Eng. 2007, 5, 928-932. [CrossRef]

10. Zhao, W.; Geng, D.; Dong, Z.; Zhou, Y. Analysis on Numerical Simulation of Heading Pilot's Excavation in Subway Station. J. Shenyang Jianzhu Univ. (Nat. Sci.) 2010, 26, 855-858. [CrossRef]

11. Guo, X.; Jiang, A.; Wang, S.; Gui, Y. Study on the Applicability of an Improved Pile-Beam-Arch Method of Metro Station Construction in the Upper-Soft and Lower-Hard Stratum. Adv. Civ. Eng. 2021, 2021, 6615016. [CrossRef]

12. Yu, L.; Zhang, D.; Fang, Q.; Cao, L.; Xu, T.; Li, Q. Surface settlement of subway station construction using pile-beam-arch approach. Tunn. Undergr. Space Technol. 2019, 90, 340-356. [CrossRef]

13. Jia, S. Analysis on Procedural Ground Settlement of Metro Station Constructed by PBA Method. Railw. Constr. Technol. 2018, 11, 72-76. [CrossRef]

14. Xu, Y.; Yu, P. Discussion on the Settlement Law of PBA Metro Station Based on Tubular Roof Method. Railw. Stand. Des. 2019, 63, 130-136. [CrossRef]

15. Li, J.; Chen, P. Comparative Analysis of Group Cave Effect in Construction of Subway Station by Pile-beam-arch (PBA) Method. Sci. Technol. Eng. 2020, 20, 5737-5742. [CrossRef]

16. Wang, Y. Settlement Analysis Caused by Excavation on Sequence of Pilot Tunnel with PBA Method. Spec. Struct. 2016, 33, 10-13. [CrossRef]

17. Ren, J.-x.; Cao, X. Research on the Surface Settlement of Subway Station Induced by PBA Construction Method. J. Railw. Eng. Soc. 2018, 35, 88-92. [CrossRef] 
18. Liu, X.; Liu, Y.; Yang, Z.; He, C. Numerical analysis on the mechanical performance of supporting structures and ground settlement characteristics in construction process of subway station built by Pile-Beam-Arch method. KSCE. J. Civ. Eng. 2017, 21, 1690-1705. [CrossRef]

19. Ji, W.; Huang, B. Influence of Double Connecting Tunnel and Bidirectional Pilot Tunnel Construction of the Pile-Beam-Arch Method on Surface Settlement. J. Anhui Univ. Sci. Technol. (Nat. Sci.) 2020, 40, 21-26. [CrossRef]

20. Shan, R.; Huang, B. The Comparison and Selection of Schemes on Pilot Tunnels' Bidirectional Excavation in Metro Stations Constructed by PBA Method. J. Shenyang Jianzhu Univ. (Nat. Sci.) 2016, 32, 200-208. [CrossRef] 